Bentham OPEN
CrossMark
Content list available at: www.benthamopen.com/TOBIOTJ/
DOI: $10.2174 / 1874070701610010407$

\title{
RETRACTION
}

\section{Retraction Notice: Risk Assessment of Cold Damage to Maize Based on GIS and a Statistical Model}

Zhewen-Zhao ${ }^{\mathrm{a}, \mathrm{b}, \mathrm{c}}$, Jingfeng-Huang, ${ }^{\mathrm{a}, \mathrm{b}, \mathrm{c},{ }^{*}}$, Zhuokun-Pan ${ }^{\mathrm{a}, \mathrm{b}, \mathrm{c}}$ and Yuanyuan-Chen ${ }^{\mathrm{a}, \mathrm{b}, \mathrm{c}}$

${ }^{a}$ Institute of Remote Sensing and Information Application, Zhejiang University, Hangzhou, 310058, China

${ }^{b}$ Key Laboratory of Polluted Environment Remediation and Ecological Health, Ministry of Education, College of Natural Resources and Environmental Science, Zhejiang University, Hangzhou, 310058, China

${ }^{c}$ Key Laboratory of Agricultural Remote Sensing and Information System of Zhejiang Province, Hangzhou, 310058, China

\section{RETRACTION}

The Publisher and Editor have retracted this article [1] in accordance with good ethical practices. After thorough investigations we believe that the peer review process was compromised. The article was published online on 02-11-2015.

\section{REFERENCE}

[1] Zhewen-Zhao, Jingfeng-Huang, Zhuokun-Pan, Yuanyuan-Chen . Risk assessment of cold damage to maize based on GIS and a statistical model. Open Biotech J 2015; 9: 236-42. 